\title{
Analysis on Thinking Model of Ship Driving Safety
}

\author{
Sheng Li \\ Qingdao Ocean Shipping Mariners College, Qingdao Shandong, 266071,China
}

Keywords: Ship driving, Safety, Thinking mode.

\begin{abstract}
Due to continuous development of science and technology, the living standard of modern people is also improved gradually. Currently, traffic safety has become a hot issue concerned by the masses. Ship transportation is always an important content in transportation industry, which has significant influence on the life of modern people. However, ship driving safety always bothers people. Various ship transportation accidents not only cause injuries and deaths, but also trigger a lot of disputes. This requires drivers to master relevant thinking model of ship driving safety and build a firewall for water transportation safety. This paper discusses thinking model of ship driving safety in four aspects, i.e. organized thinking mode, oriented thinking mode, essential thinking mode and global thinking mode.
\end{abstract}

\section{Introduction}

Water ship driving has strong practicalness and extremely high risk. It is one of the trades with significant individual characteristics. According to an investigation, among many ship transportation accidents, over $80 \%$ are caused by human factors. As is known to us, motion state of a ship is mainly determined by drivers' instructions and their degree of control over machine. This process involves psychological status of drivers. Their principle, position, motivation and method of considering problems show their thinking mode. Therefore, ship driving safety can be maintained better through study on thinking mode of ship driving safety and its proper application.

\section{Organized thinking mode}

Organized feature can be regarded as an important feature of logical thinking. That is to say, inevitable conclusion can be made through correct performance of the whole process. Organized thinking mode is mainly characterized by full advance preparation, detailed plan for implementation, corresponding steps of operation and adequate scheme to cope with changes. It is required to make fast response, take reasonable measures and link the past and the future in the driving process. This plays a vital role in ship drivers' mastery of seamanship in practice. It is mainly manifested in two aspects as below:

On the one hand, good knowledge of process should be possessed. This knowledge is one of the specific temperament making ship drivers seem well trained. Drivers should develop good habits in the practice of ship driving. That is to say, before conducting an operation, they should determine reasonable operational steps according to current environment and conditions in advance, then implement them step by step according to their requirements and make reasonable adjustments according to continuous change of specific environment and circumstances so as to realize the effect of clear thought, orderliness and continuous operation.

On the other hand, the predictability of ship driving operation should be improved. Predictability should be called as centralized manifestation of advanced ship operation technology, which mainly covers contents in four aspects below: first, mastery of basic motion state of the ship driven, including track, speed and course etc.; second, prediction of corresponding action that other ships might take; third, possible situations under some specific circumstances such as certain time period, leg and work stage; forth, countermeasures that the ship should have. After full application of predictability measures above, it is required to master positive measures for coping with emergency so as to prevent the occurrence of dangerous and complicated situations more effectively. Even if danger occurs, 
various effective measures should be taken immediately to avoid accidents to the greatest extent. Therefore, the development of predictability thinking requires ship drivers to learn and communicate and accumulate work experience at ordinary times.

\section{Oriented thinking mode}

Orientation mainly refers to one of the value orientation that should be possessed by people. Meanwhile, orientation has close relation with the position and motivation of thinking problems. It often shows individual features of people with various habitual forms of people. Ship drivers are engaged in extremely boring and heavy work combining mental and physical strength for a long term. This requires ship drivers to have strong will. As the operating post of ship drivers is highly dangerous, ship drivers should make reasonable professional orientation with their strong will and undertake due responsibilities. In specific navigation practice, positive career orientation is the most basic external manifestation mode. Only with adequately strong wisdom and clear individual goal can ship drivers have adequate enthusiasm in work, learn continuously, be eager for more knowledge, think more independently and be bold in practice. Ship drivers should not only have clear career planning, but also have positive ship occupation position. Occupation position of ship drivers is that they should regard ship driving as a personal career for pursuit and struggle so as to realize their life value in the real sense. Let's take the orientation of ship drivers in South China Sea Rescue Bureau of Ministry of Transport for example. South China Sea Rescue Bureau of Ministry of Transport established in June 2003 is a first-level public institution directly under the Ministry of Transport of China as well as a professional marine salvage institution at national level. It is mainly responsible for water rescue for various domestic and foreign ships, water-borne facilities and equipment, various aircrafts in danger and other aspects within the area of South China Sea, marine fire prevention for the purpose of life salvage and rescue of ship and marine facilities and properties for direct purpose of life rescue. Under unified leadership of the Ministry of Transport, South China Sea Rescue Bureau has four rescue helicopters respectively on duty in three rescue stations namely Zhuhai, Zhajiang and Sanya, thus establishing a new salvage system with sea and air integration. Functions above require ship drivers of South China Sea Rescue Bureau to be able to cope properly in various situations. Faced with various dangers, they should rescue ships and their passengers encountering danger boldly. Workers in South China Sea Rescue Bureau have positive oriented thinking awareness, always make others' life safety superior to their own safety and regard positive rescue of others as a main way to achieve personal outlook on life and value so as to guarantee life safety of people.

\section{Essential thinking mode}

Essential thinking mode mainly means that main operation methods of ship should be used flexibly according to the change of objective situation. Drivers who do not master corresponding methods or cannot use such methods flexibly will be hurry-scurry in actual operation, i.e. they fail to grasp the main points. Twice the result can be yielded with half the effort through measure adjustment based on local conditions, flexible application, reasonable change and mastery of main points.For example, when a ship enters the wharf, the most basic operating factors are birthing angle, departure and deflection under the current environment. The ship should be operated and controlled with operation manner so as to complete the process of birthing reasonably. This is the whole process of handling the relationship among various basic factors properly. Main points are abstract and can be understood tacitly through perception with heart, repeated consideration, comprehensive analysis and mastery of objective law. To master main points of ship driving, the following three points shall be realized:

First, rich knowledge and experience. Knowledge and experience can be called as the most fundamental conditions for mastering main points. Knowledge should be learnt and accumulated at ordinary times. Experience should be perceived with heart and accumulated in practice. Both are equally important for reflecting main points. Some people often think that ship driving only requires fixed things and does not require study of new knowledge or summary of experience. In fact, if ship 
drivers are really careless, they will be at a loss in dangerous cases. This can be called as mediocrity. There are many high-level ship drivers in reality who practice carefully and pay attention to accumulate the required knowledge and experience at ordinary times. Therefore, they can do things with high proficiency in the operational process. Even when facing a tense situation, they can face the music, show their talents comprehensively and turn the corner or minimize losses.

Second, enlightened thinking. Enlightenment mainly means that ship drivers should keep quick thinking and open mind and comprehend by analogy rather than follow bigoted course and stick to convention. However, some people have blocked thinking mode and do not take others' advice. Once an accident occurs, they often emphasize objective reason during analysis and do not learn lessons. That means, they cannot get the point. To enlighten their thinking, it is required to acknowledge that personal knowledge and experience are limited and the main reason for accidents is human. Meanwhile, the change of everything is complicated. Only with hard efforts and wisdom can people find solutions for relevant problems. Only with good understandings and attitude can one learn modestly and summarize in detail.

Third, active inspiration. Inspiration originates from rich knowledge, experience and strong passion about being engaged in ship industry and is the practice of wisdom produced through careful learning and thinking and positive summary. Ignorant and numb people often lack adequate inspiration and have blocked thinking in the process of ship driving. Just as falling into a dream, they cannot draw a clear distinction between the primary and the secondary or master the overall situation accurately. They have sluggish response and seem hurry-scurry at a critical juncture. Therefore, accidents occur naturally. To avoid accidents, they only depend on fortune. Ship drivers with rich knowledge and experience and passion have flexible thinking and sensitive reaction and can draw a clear distinction between the primary and the secondary. They can cope with crisis placidly and avoid accidents or minimize losses to the greatest extent.

\section{Global thinking mode}

When driving a ship in dynamic and complicated environment, especially at the approach of danger, drivers generally take measures with an idea that suddenly comes to mind. Decision-making without comprehensive consideration generally causes serious consequences. An idea of ship drivers that suddenly comes to mind in the driving process might be a wrong move caused by position and motivation error or inadequate knowledge and experience or other instinctive reactions, vanity and fluke mind. To prevent momentary slip, drivers should have global thinking and master the following four principles: first, better be early than late and try to take initiative. That is to say, drivers should take measures rapidly after comprehensive prediction and estimation of the current situation so as to avoid getting into a more urgent situation. It is the best plan to take powerful countermeasures rapidly to avoid danger before its occurrence. It is the worst way to take countermeasures for remediation after constant accumulation of adverse factors and the occurrence of a more urgent situation. Never getting into a dangerous situation is the highest state of ship drivers. Less access to tense situation can effectively avoid accidents, which can be called as strong skill. Frequent entry into the state of emergency will inevitably cause accidents in the long term. Such drivers cannot be considered qualified. Second, leave some leeway and avoid getting into hopeless situation. Emergency action should be taken in time to avoid danger. Some leeway should be left for everything. Third, face the reality and make a prompt decision. In the case of state of emergency, the most reasonable attitude and selection should be facing the reality and making a prompt decision. Ship drivers should take the most reasonable countermeasures decidedly according to current actual situation so as to avoid missing the appropriate opportunity for disposal due to hesitation. Drivers should not have fluke mind or take other wrong actions to cover previous wrong actions which will inevitably pour oil on the flames. Finally, better minor than major and reduce losses. Once losses cannot be avoided, ship drivers should spare no pains minimizing losses. 


\section{Conclusion}

In conclusion, various water traffic accidents occur constantly with rapid development of ship transportation industry, most of which are caused by human factors. In actual ship driving, personal thinking mode of drivers always controls the state of their ship. On the contrary, the motion of ship can also reflect the thinking mode, position and motivation of drivers. Therefore, safe operation of a ship is mainly controlled by drivers' thinking. The thinking mode of people does not always remain unchanged. It is related to their cultural literary, value and experience. Therefore, safety thinking mode of ship drivers requires them to not only have positive and optimistic concept of life and careful work style, but also put life safety of passengers in the most important position and always concentrate during driving so as to guarantee ship driving safety to the greatest extent.

\section{References}

[1] Wang Guodong. Navigation Bridge Resource Management and Navigation Safety of Ships, Science and Technology Communication, 2013, (22).

[2] Dong Di. Analysis on Ship Navigation Safety under Navigation Bridge Resource Management, World Shipping, 2015, (2).

[3] Sun Jixiang. Analysis on Navigation Bridge Resource Management and Navigation Safety of Ships, Private Science and Technology, 2017, (2).

[4] Wu Zhongsheng. Relationship between Navigation Bridge of Captain on Duty and Navigation Safety, Navigation, 2017, (2). 